\title{
Rifamide in Acute Cholecystitis and Biliary Surgery
}

\author{
P. G. BEVAN, J. D. WILLIAMS
}

\section{Summary}

Determination of the minimum inhibitory concentrations of rifamide necessary to inhibit organisms isolated from the biliary tract showed that the organisms were almost invariably sensitive to concentrations which are readily attainable in the biliary tract. Three cases of severe acute infiammation of the biliary tract were treated and this led to rapid clinical improvement. In 61 patients undergoing biliary surgery a random group was given rifamide $150 \mathrm{mg}$ twice daily, beginning 24 hours before operation and continuing for three days afterwards. In the untreated group eight patients had infected bile at operation and five subsequently developed a wound infection. In the rifamide group three had infected bile at operation and only one developed a wound infection. A similar number of postoperative chest infections occurred in each group of patients. There is some evidence of reduction in length of hospital stay in the treated patients.

\section{Introduction}

Operations on the biliary tract carry a definite incidence of postoperative infection which falls into two groups-wound infection and infections involving the biliary tract and the associated area of peritoneum. In the latter group severe complications occasionally ensue, such as subphrenic abscess and even septicaemia (Maingot, 1963). Contamination during operation may lead to wound infection with Gram-negative bacilli or Streptococcus faecalis from the infected bile, perhaps aided by the spreading quality of bile resulting from its low surface tension. A further predisposing factor to wound infection is increased obesity of the abdominal wall, also making chest infection more likely. Infections of the biliary tract can progress to cholangiohepatitis, pancreatitis, or local peritonitis, especially in the presence of stones or stricture formation in the common bile duct, with or without obstruction.

The antibiotics most commonly used to treat acute cholecystitis and to "cover" operations on the infected gall bladder are tetracycline and ampicillin, as these reach high concentrations in the bile (Ayliffe and Davies, 1965).

The rifamycin group of antibiotics are derived from Streptomyces mediterranei, and one of the group, rifamycin $\mathrm{B}$, is the parent substance of two compounds recently introduced into England by Lepitit Laboratories. The antibacterial spectrum of the two compounds is similar and includes activity against mycobacteria. Rifampicin is being used to treat tuberculosis. Rifamide (Rifocin) is mainly excreted in unchanged form in the bile, and bile levels after a 100-mg dose intramuscularly can reach more than 1,000 $\mu \mathrm{g} / \mathrm{ml}$ (Fürész et al., 1965; Stratford and Dixson, 1966). These levels exceed the minimum inhibitory concentrations of most Gram-negative bacilli likely to be found in bile-Escherichia coli, Klebsiella, Salmonella, and Proteus spp.,

Dudley Road Hospital, Birmingham 18

P. G. BEVAN, F.R.C.S., Consultant Surgeon

J. D. WILLIAMS, M.D., M.R.C.PATH., Consultant Microbiologist

and Str. faecalis (Fürész et al., 1965). These levels are higher than those of antibiotics commonly used for biliary infections, including tetracycline, ampicillin, novobiocin, and erythromycin. The levels in the wall of the gall bladder are also high.

We have used rifamide therapeutically in patients with acute cholecystitis before operation and prophylactically in patients with gall stones undergoing biliary surgery with or without chronic cholecystitis. This paper describes the results.

\section{Methods}

Acute Cholecystitis.-Diagnosis was based on the typical clinical syndrome-pain, tenderness, and guarding in the right subcostal region, with malaise, nausea, and vomiting. The patients looked toxic and sometimes showed mild jaundice. Infections of the respiratory and urinary tracts were excluded radiologically and by bacteriological examination of the sputum and urine. Rifamide $150 \mathrm{mg}$ twice daily was given intramuscularly for periods varying from 5 to 10 days. Some patients had previously been treated with other antibiotics.

Prophylactic Use in Biliary Tract Surgery.-Patients undergoing biliary surgery were selected for study if they had been seen 24 hours before the operation was performed. Most were admitted from the waiting list but some were emergency admissions with gall stone colic or cholecystitis. Patients were allotted to treatment or control groups on a random number basis, the surgeon being unaware of the administration of rifamide. Other antibiotics were given when indicated clinically or on bacteriological evidence, the only limitation on their use being that reasons for using them had to be clearly stated.

Dosage.-Patients in the rifamide group received $150 \mathrm{mg}$ of rifamide twice daily starting 24 hours before operation and continuing for three days afterwards.

Clinical Methods.-Records collected included data on previous gall bladder disease and chest disease, clinical features preoperatively, extent of inflammation of the gall bladder at operation, and clinical evidence of infection postoperatively. Histological studies of the gall bladder were made to show the presence and degree of cholecystitis. Each section of the record card was completed at the appropriate time and the final section on discharge of the patient from hospital.

Laboratory Methods.-Nasal swabs and sputum were collected on admission from patients in the study group. Bile from the gall bladder and common bile ducts was collected at operation, for cultures and identification of organisms, and postoperatively when drainage of the common bile duct was carried out. Organisms were cultured from any wound infection which occurred. Minimum inhibitory concentrations of rifamide for all organisms isolated were measured by a tube dilution technique with a range of 1 to $500 \mu \mathrm{g}$ of rifamide and an innoculum of $10^{5}$ organisms per tube.

\section{Results}

Sixty-five patients were admitted to the main study but four were discarded as bile cultures were not made, leaving $61-34$ in the rifamide group and 27 in the control group. A comparison of these groups is made in Table $I$. There were rather more males in the control group. Three patients in the rifamide group had previously undergone gall bladder surgery. Most of the patients had inflammatory disease of the gall bladder, and 
TABLE I-Comparison of the Two Groups of Patients Undergoing Cholecystectomy

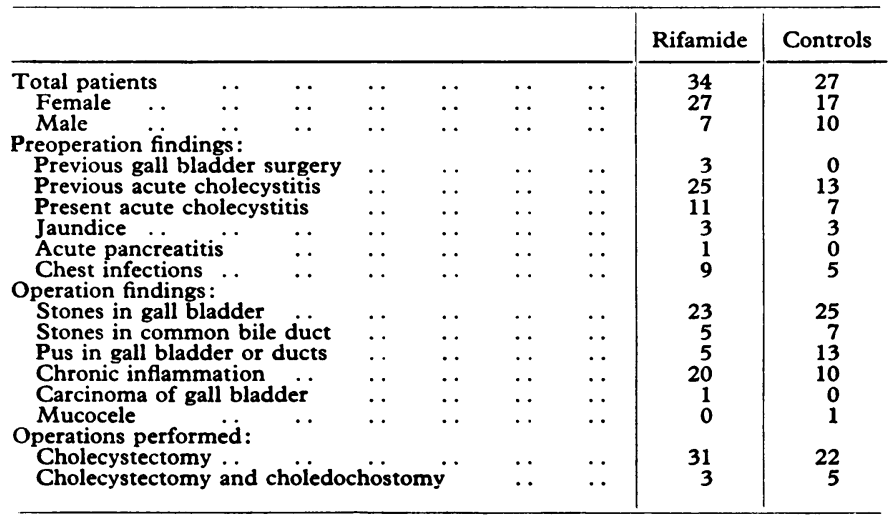

TABLE II-Infections arising in Two Groups of Patients

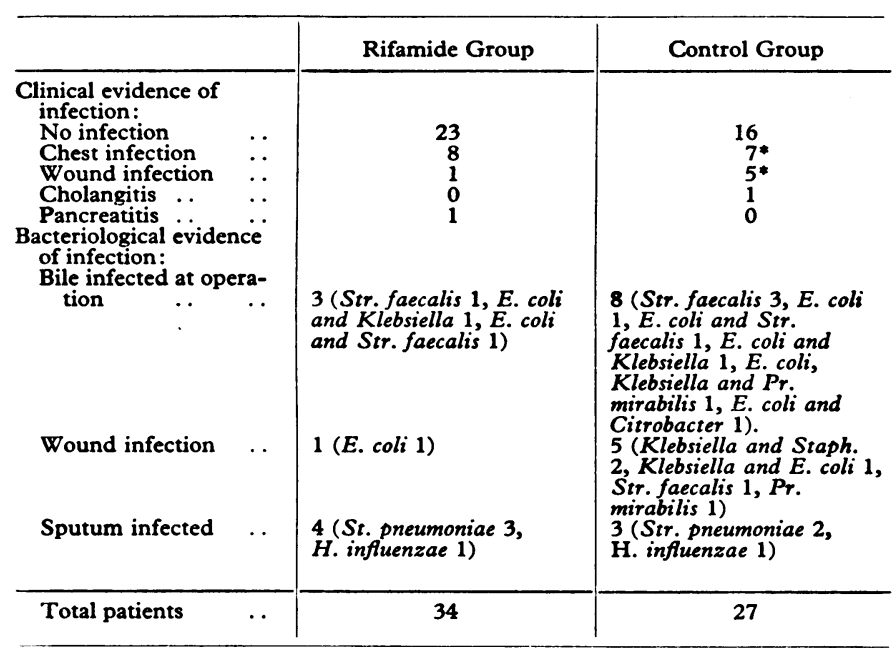

* Three patients had both chest and wound infection

TABLE III-Antibiotic Administration and Length of Hospital Stay in the Two Groups of Patients

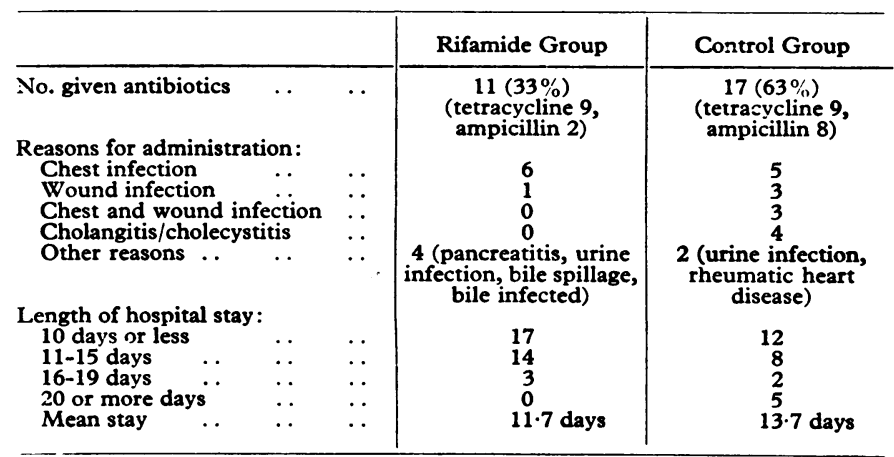

TABLE IV-Effect of Acute Cholecystitis on the Outcome of Cholecystectomy

\begin{tabular}{|c|c|c|c|c|}
\hline & \multicolumn{2}{|c|}{$\begin{array}{l}\text { Patients with Acute } \\
\text { Cholecystitis on Admission }\end{array}$} & \multicolumn{2}{|c|}{$\begin{array}{l}\text { Patients with Previous } \\
\text { Attacks of Acute Cholecys- } \\
\text { titis but No Present } \\
\text { Acute Episode }\end{array}$} \\
\hline & $\begin{array}{l}\text { Rifamide } \\
\text { Group }\end{array}$ & $\begin{array}{l}\text { Control } \\
\text { Group }\end{array}$ & $\begin{array}{l}\text { Rifamide } \\
\text { Group }\end{array}$ & $\begin{array}{c}\text { Control } \\
\text { Group }\end{array}$ \\
\hline $\begin{array}{l}\text { No. of patients } \\
\text { Infected bile at operation } \\
\text { Infected wounds } \\
\text { Mean hospital stay } \ldots \\
\text { Antibiotics used other } \\
\text { than rifamide }\end{array}$ & $\begin{array}{c}11 \\
1 \\
0 \\
12 \cdot 7 \text { days } \\
3\end{array}$ & $\begin{array}{c}7 \\
3 \\
3 \\
20 \cdot 7 \text { days } \\
6\end{array}$ & $\begin{array}{c}18 \\
2 \\
1 \\
11 \cdot 1 \text { days } \\
7\end{array}$ & $\begin{array}{c}10 \\
3 \\
1 \\
13 \cdot 1 \text { days } \\
6\end{array}$ \\
\hline
\end{tabular}

one mucocele was found at operation. Apart from these findings the groups showed similar features.

Table II shows the incidence of clinical infection at several sites in the two groups and the results of bacteriological examination. A similar percentage of chest infections occurred in the two groups. In the control group one patient developed ascending cholangitis and five patients developed wound infections, the organisms isolated from these wounds being of faecal origin, but two wounds acquiring a staphylococcus in addition. Only one patient in the rifamide group developed clinical wound infection. Cultures of bile from the rifamide group yielded five organisms from three patients, and in the control group 13 organisms from eight patients $(t 2 \cdot 1, \mathrm{P}<0.05)$. Organisms were isolated from sputum with equal frequency in both groups. Antibiotics were given significantly more often in the control group, where $63 \%$ of the patients needed antibiotic therapy, compared with $33 \%$ in the rifamide group $(t 2.38, \mathrm{P}<0.05)$. In the rifamide group antibiotics were given predominantly for chest infections (Table III). The average length of stay in hospital postoperatively did not differ appreciably, but all the rifamide-treated patients were discharged on or before the eighteenth postoperative day, whereas five of the control group remained for 20 or more days.

The effect of the presence of acute cholecystitis on the outcome of operation is shown in Table IV. Of the seven patients with evidence of acute inflammation at the time of operation who received antibiotics other than rifamide (and were therefore in the control group), three had infected bile and the same three subsequently developed wound infections. These seven patients stayed in hospital an average of 20.7 days postoperatively $(10,13$, $16,20,21,24$, and 43 days), significantly longer than the $12 \cdot 7$ days of 11 patients with acute cholecystitis receiving rifamide $(10,10,10,10,12,13,13,14,14,15$, and 17 days $)$. When there was evidence of past acute infection but no present acute episode, the differences between the two groups of patients was less pronounced (Table IV).

The sensitivity of the organisms isolated from the biliary tract of the patients in the two groups is shown in Table V. In the rifamide group one organism, an $E$. coli, was found to be resistant to more than $500 \mu \mathrm{g}$ of rifamide per ml., and this was in the only patient in the group to develop a wound infection, the same strain of $E$. coli being isolated. All the organisms isolated from the control group were inhibited by $500 \mu \mathrm{g} / \mathrm{ml}$ and all but two by $100 \mu \mathrm{g} / \mathrm{ml}$.

\section{Acute cholecystitis}

In this series 18 patients were admitted with acute cholecystitis (Table IV); 11 of these were in the rifamide group and eight were clinically mild, while six of the seven in the control group were mild. Clinically, there was no marked difference in the response to preoperative treatment of the mild cases in the two groups. However, the three severe cases showed a pronounced response to rifamide, with improvement in the general condition, resolution of pyrexia, and localization with lessening of the abdominal signs; an operation of election was possible in all three cases. The severe case in the control group, treated with tetracycline, showed no such response to treatment and needed an emergency operation $\mathbf{4 8}$ hours after admission.

TABLE V-Minimum Inhibitory Concentrations of Rifamide for Organisms isolated from Gall Bladders

\begin{tabular}{|c|c|c|c|c|c|c|c|c|}
\hline & Total & $<1$ & $1-10$ & $11-20$ & $21-50$ & 51-100 & $101-500$ & $>500$ \\
\hline $\begin{array}{l}\text { Control patients: } \\
\text { Str. faecalis }\end{array}$ & & 2 & & & & - & & \\
\hline E. coli & $\begin{array}{l}4 \\
5 \\
2\end{array}$ & $\frac{2}{-}$ & $\bar{z}$ & 2 & 2 & - & 1 & 二 \\
\hline $\begin{array}{l}\text { Klebsellla spp. } \\
\text { Pr. mirabilis. }\end{array}$ & 2 & 三 & $\overline{1}$ & 1 & 二 & $\frac{1}{-}$ & 二 & 二 \\
\hline $\begin{array}{l}\text { Citrobacter } \\
\text { Rifamycin patients: }\end{array}$ & & & & & - & 1 & & \\
\hline $\begin{array}{l}\text { Str. faecalis } \\
\text { E. coli } \quad . .\end{array}$ & 2 & $=$ & 1 & 三 & $\overline{1}$ & 1 & 三 & $\overline{1}$ \\
\hline
\end{tabular}


The following is the case report of a further patient with severe biliary infection who responded to rifamide.

Case Report.-A man of 69 was admitted to hospital on 19 September 1969 with a history of mild jaundice, loss of weight, tiredness, and sweats for the previous four months. Three years previously he had undergone cholecystectomy for gall stones at another hospital. He had experienced recurrent attacks of jaundice and fever since the operation. On examination he was thin, toxic, and mildly jaundiced with a moderately enlarged and tender liver. Investigations showed: E.S.R. $55 \mathrm{~mm} / \mathrm{hr}$, Hb $99 \%$, W.C.C. 5,000/ $\mathrm{mm}^{3}$, serum bilirubin $3.4 \mathrm{mg} / 100 \mathrm{ml}(2.7 / 100 \mathrm{ml}$ conjugated $)$, serum alkaline phosphatase $37 \cdot 2$ K.A. units. He was running a high swinging pyrexia (up to $103^{\circ} \mathrm{F}\left(39.4^{\circ} \mathrm{C}\right)$ daily, which showed no response to tetracycline and sulpamezathine (see Chart). Rifamide brought his temperature down to normal in 24 hours and he remained apyrexial
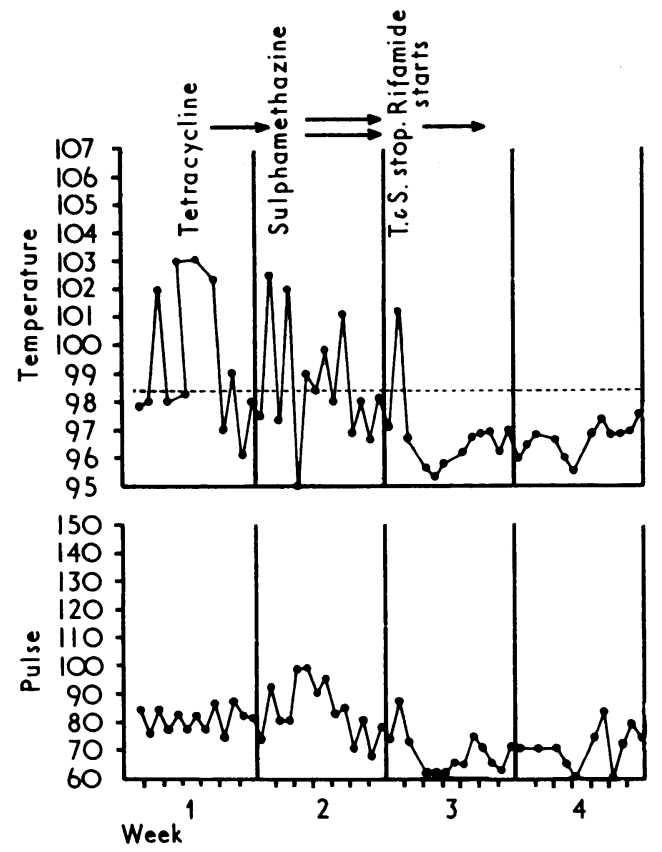

Temperature chart of patient with cholangitis, showing immediate response to rifamide following no response to tetracycline and sulphamezathine.

until the operation 13 days later, with considerable improvement in general condition. At operation the common bile duct was very dilated with the lower third full of stones; operative cholangiography showed gross hydrohepatosis; the liver was the seat of severe biliary cirrhosis (confirmed by biopsy), and there was diffuse chronic pancreatitis. Choledochostomy was performed, all the stones were removed, and $\mathrm{T}$-tube drainage was instituted. He made an uncomplicated recovery.

Bacteriological studies of the 18 patients with acute cholecystitis in the study group showed that in the rifamycin group, 1 out of 11 patients yielded infected bile at operation, in contrast to three out of seven in the control group. All three control patients developed infected wounds, but none did so in the rifamide group.

\section{Discussion}

It has been confirmed by many authors that calculous disease of the biliary tract is usually attended by biliary infection leading to a high incidence of biliary complications and wound infections. The series of chronic cholecystitis reviewed by Larmi et al. (1958) gave incidence of 33 to $36 \%$ of positive cultures from the biliary tract. Robson et al. (1970) found 10 postoperative wound infections occurring in 65 cholecystectomies and eight yielded positive cultures from the biliary tract. In seven the organism from the wound was identical with that in the biliary tract, indicating endogenous infection. Mason (1968) noted 10 wound infections in 14 patients with positive biliary tract infection, eight with identical organisms. In a prospective study, Watson (1969) found an incidence of $61 \%$ of positive biliary cultures in patients with acute cholecystitis.

In a survey of wound infection in general surgery, Robertson (1958) found that biliary operations formed the second commonest group, involving $6 \%$ of cases. Payne (1969) found an incidence of $5 \%-43$ wound infections in 924 biliary operations. These were both retrospective surveys, and the real incidence is probably higher. Robson et al. (1970) found an incidence of $15 \%$, similar to the incidence in our series of control patients, where 5 out of 27 patients $(18 \%$ ) had a wound infection (Table II). The organisms present in the gall bladder at operation bear a direct relationship to the resulting wound infection when this occurs. In all cases with wound infection the same organism was invariably found also in the gall bladder. The presence of an organism in the gall bladder did not necessarily lead to a wound infection, but no cases of wound infection occurred in patients in whom the bile was sterile at operation. It therefore seems important to try to sterilize the bile before operation is undertaken. The high prevalence of infected bile is shown by the fact that 8 of the 27 control cases had infected bile at operation, despite previous antibiotic therapy in several cases. The use of rifamide before operation substantially reduced the number of patients with infected bile.

Before the introduction of rifamide the two antibiotics mainly used in biliary infections were tetracycline and ampicillin, because these antibiotics are the only two which are concentrated in bile and which have, in addition, a therapeutically acceptable activity against the likely pathogens. The levels of rifamide attainable in the biliary tract also exceed the minimum inhibitory concentration of practically all strains. The only rifamycin-resistant strain isolated was from a patient who had been receiving rifamycin before operation. This strain was not isolated from the bile at operation but was grown from a T-tube two days subsequently.

The objective in giving rifamide to patients undergoing biliary surgery is to sterilize the bile, and therefore the high levels obtainable have some significance. In treating acute cholecystitis and cholangitis, however, the level in the bile might not be so important as the level of the antibiotic which is attainable in the liver tissue. The rapid response of acute cholecystitis to rifamide suggests that the levels in the liver substance may be quite high, because the minimum inhibitory concentration of rifamycin for Gram-negative bacilli is commonly in the neighbourhood of $20-50 \mu \mathrm{g} / \mathrm{ml}$ - that is, higher than the blood level of the antibiotic.

Prophylactic antibiotic therapy is often used in surgery, but because many of the uses appear to be empirical this type of therapy is usually frowned on. The reasons for considering such therapy in biliary surgery are that the gall bladder is often infected and wound infections are common after cholecystectomy. The organisms found in the gall bladder are usually derived from the bowel, and at the levels attained by rifamide in the bile most infecting organisms are sensitive.

Residual infection in the bile after cholecystectomy can lead to recurrent stone formation in the common bile duct. A further justification for prophylaxis is to establish sterility of the bile from the time the gall bladder is removed. In order to reach an effective concentration in the bile the rifamide was given for 24 hours beforehand.

Another bacteriological characteristic of rifamide thought to be of possible value was its high activity against the respiratory pathogens Str. pneumoniae and $H$. influenzae. However, the incidence of chest infection was the same in both groups of patients. This is probably related to the poor penetration of rifamycin into the bronchial secretion (Citron and May, 1969). 
We wish to thank Miss Linda Glaze for technical help and Miss Vivian Barlow for secretarial services. Dr. C. D. Granger, of Lepetit Pharmaceuticals, kindly arranged a generous supply of rifamide (Rifocin-M).

\section{References}

Ayliffe, G. A. J., and Davies, A. (1965). British fournal of Pharmacology and Chemotherapy, 24, 189.
Citron, K. M., and May, J. R. (1969). Tubercle, 50, 329.

Fürész, S., Arioli, V., and Scotti, R. (1965). Arzneimittel-Forschung, 15, 802 Larmi, T. K., Fock, G., and Vuopio, P. (1958). Acta Chirurgica Scandinavica, 114, 379

Maingot, R. (1963). Annals of the Royal College of Surgeons of England, 32, 42. Mason, G. R. (1968). Archives of Surgery, 97, 533.

Payne, R. A. (1969). British Fournal of Surgery, 56, 200.

Robertson, H. R. (1958). Annals of the Royal College of Surgeons of England,

23, 141. C., Bogart, J. N., and Heggers, J. P. (1970). Surgery, 68, 471.

Stratford, B. C., and Dixson, S. (1966). Medical fournal of Australia, 1, 1.

Watson, J. F. (1969). Military Medicine, 134, 416.

\title{
Controlled Comparison of the Efficacy of Fourteen Preparations in the Relief of Postoperative Pain
}

\author{
J. D. MORRISON, W. B. LOAN, J. W. DUNDEE
}

British Medical fournal, 1971, 3, 287-290

\section{Summary}

Thirteen analgesic drugs, four of them at two dose levels, four analgesics in combination with antagonist or neuroleptic agents, and saline have been evaluated simultaneously in the relief of postoperative pain. The method of assessment was designed to favour drugs which provided freedom from pain with minimum depression of consciousness. Only levorphanol $2 \mathrm{mg}$ proved significantly superior to pethidine $100 \mathrm{mg}$, which was used as the standard reference drug. Oxycodone $10 \mathrm{mg}$, pentazocine $20 \mathrm{mg}$, and the morphine $10 \mathrm{mg}$ and cyclizine $50 \mathrm{mg}$ combination were the most successful of the remaining drugs. None of the drug combinations was significantly better than the analgesic drug given alone.

\section{Introduction}

There are several possible approaches to the symptomatic relief of severe pain-namely, interruption of afferent nerve pathways, either chemically or surgically; "dissociation" of the patient from his pain, which may be achieved by such psychological devices as suggestion or hypnosis, or pharmacologically by agents such as chlorpromazine ; and use of centrally acting analgesics, which may also produce mild sedation and dissociate patients from their pain. Only the latter, which involves the systemic use of drugs with opiate-like actions, offers ease of administration compatible with everyday clinical practice. It is therefore of importance that the relative merits of the numerous available drugs of this class should be established. Though the literature relating to these substances is abundant reports have usually encompassed only a few agents, and lack of standardized methodology makes the compiling of an overall assessment difficult.

The study reported here, which occupied four years, was undertaken to answer this need.

Department of Anaesthetics, the Queen's University of Belfast, and Royal Victoria Hospital, Belfast, Northern Ireland

I. D. MORRISON, M.D., F.P.A. R.C.S., Senior Registrar

J. W. DUNDEE, M.D., F.F.A. R.C.S., Professor of Anaesthetics

Belfast City Hospital

W. B. LOAN, M.D., P.F.A. R.C.S.I., Consultant Anaesthetist

\section{Method and Material}

The method has been previously described and presented with a critical assessment of its sensitivity and validity (Loan et al., 1968). Patients who had undergone upper or lower abdominal surgery were admitted to the trial when the nursing staff considered that they required their first postoperative analgesic. Pain severity was assessed before and after treatment on four criteria-namely, patient's and observer's subjective estimates on a five-point scale and, with upper abdominal wounds, measurements of vital capacity and peak expiratory flow rate. Pain relief was inferred from changes in these criteria and also estimated by the patient's direct retrospective comparison with his pretreatment state. Treatment in any individual patient was classified as a success only when all these criteria showed improvement, and this "overall" assessment was used in the final comparison of drugs.

The study was carried out in the same environment by two observers who were successive full-time research workers. Drugs were administered and assessments made under doubleblind conditions.

The preparations, doses, and numbers of patients given each drug are listed in Table $I$, and mean ages and weights of patients are shown in Table II. Ideally, each drug should be included at several dose levels so that the basis of comparison would be dose/response curves, thus eliminating differences due solely to dosage. In practice such an approach would have required a vastly greater number of subjects and would have extended the time far beyond the four years taken to complete this study, which was mainly concerned with com-

TABle I-Details of Drugs and Dosages used.

\begin{tabular}{|c|c|c|c|c|c|c|c|c|c|}
\hline & & & & & & & & $\begin{array}{l}\text { Dose } \\
\text { (mg) }\end{array}$ & $\begin{array}{l}\text { No. of } \\
\text { Patients }\end{array}$ \\
\hline Morphine & .. & . & .. & . & .. & $\cdots$ & .. & \multirow{14}{*}{$\begin{array}{c}10 \\
15 \\
5 \\
20 \\
10 \\
50 \\
2 \\
2 \\
20 \\
40 \\
10 \\
5 \\
100 \\
1 \\
2 \\
0.1 \\
0.2 \\
100 / 1 \cdot 25 \\
10 / 50 \\
0.2 / 5 \\
2 / 5\end{array}$} & \multirow{14}{*}{$\begin{array}{l}80 \\
20 \\
20 \\
20 \\
20 \\
40 \\
40 \\
20 \\
20 \\
40 \\
20 \\
20 \\
40 \\
20 \\
40 \\
20 \\
40 \\
20 \\
20 \\
40 \\
40\end{array}$} \\
\hline $\begin{array}{l}\text { Diamorphine } \\
\text { Papaveretum }\end{array}$ & . & .. & . & . & .. & . & .. & & \\
\hline $\begin{array}{l}\text { Papaveretum } \\
\text { Oxycodone }\end{array}$ & $\because$ & . & $\cdots$ & $\because$ & . & $\because$ & $\because$ & & \\
\hline Dihydrocodeine & & $\because$ & $\because$ & $\therefore$ & .. & $\therefore$ & $\ldots$ & & \\
\hline Levorphanol & . & .. & .. & . & . & . & $\cdots$ & & \\
\hline Phenazocine & . & . & $\cdots$ & $\cdots$ & $\cdots$ & $\cdots$ & $\cdots$ & & \\
\hline Pentazocine & . & . & . & . & .. & .. & . & & \\
\hline Methadone & $\therefore$ & . & . & . & .. & . & .. & & \\
\hline $\begin{array}{l}\text { Dextromoramide } \\
\text { Pethidine }\end{array}$ & & $\because$ & $\because$ & $\therefore$ & .. & $\because$ & $\because$ & & \\
\hline Phenoperidine & .. & . & .. & .. & .. & $\ldots$ & .. & & \\
\hline Fentanyl .. & $\ldots$ & $\ldots$ & $\ldots$ & $\ldots$ & .. & $\ldots$ & .. & & \\
\hline Pethidine/levallo & orphan & $\ldots$ & .. & .. & .. & .. & .. & & \\
\hline & zine & & . & . & . & . & .. & & \\
\hline & $\begin{array}{l}\text { ridol } \\
\text { droperid }\end{array}$ & & $\because$. & $\because$ & $\because$ & $\because$ & $\because$ & & \\
\hline Fenoperiome & & & & & & & & & \\
\hline
\end{tabular}

